\title{
Expressões fenológicas de palmeiras em coleções botânicas associadas às condições pluviais na Floresta Tapajós
}

A família Arecaceae está incluída nas hiperdominâncias no bioma Amazônia, tendo muitas espécies de interesse às populações locais. Objetivou-se avaliar registros fenológicos herborizados de palmeiras associados à precipitação pluvial na Flona Tapajós e seu entorno. Dados nos herbários da Embrapa Amazônia Oriental (IAN/EMBRAPA) e do Museu Paraense Emílio Goeldi (MPEG) foram contabilizados avaliando informações fenológicas de Arecaceae. Também, foram avaliados dados pluviais disponíveis de Belterra, Santarém e Rurópolis. Foram contabilizados os dados pluviais e avaliados com base nas datas de floração e/ou frutificação, descrita nos registros dos herbários. Também, avaliou-se o total pluvial nos dois meses anteriores, como indicativo do volume hídrico, nas áreas de ocorrência das palmeiras. Foram encontradas 34 espécies com predominância dos gêneros Bactris, Geonoma e Oenocarpus, sendo que o Oenocarpus bataua Mart. (patauá) apresentou a maior frequência, nos registros. A floração e/ou frutificação predominou no mês de novembro. No trimestre menos pluvioso (agosto a outubro) as chuvas foram inferiores a $50 \mathrm{~mm}$, indicando que essa expressão fenológica no mês que inicia o período de chuvas esparsas na região apresenta-se como estratégia de perpetuação das espécies analisadas e conclui-se que em materiais botânicos herborizados é possível avaliar respostas à condições climáticas na Amazônia.

\section{Phenological expressions of palms trees in botanical collections associated with rainwater conditions in the Tapajós Flona}

\begin{abstract}
The Arecaceae family belongs to the Amazon biome's hyper dominances, many species being of interest for local populations. This work aimed at assessing palm trees herborized phenological records, associated with rainfall in the Tapajós National Forest and surroundings. Data from the herbaria of Embrapa Eastern Amazon (IAN / EMBRAPA) and Goeldi Museum (MPEG) were recorded to assess Arecaceae phenological information. We assessed the available rainfall data from Belterra, Santarém and Rurópolis. Rainfall data were recorded and assessed based on flowering and/or fruiting dates, as described in the herbaria records. We also assessed the rainfall total in the previous two months, as an indicator of water volume in palm trees occurrence areas. We identified 34 species with predominance of Bactris, Geonoma and Oenocarpus genera, Oenocarpus bataua Mart. (patauá) showing the highest frequency in the records. Flowering and/or fruiting prevailed in November. In the less rainy trimester (August-October) rainfall was less than $50 \mathrm{~mm}$, indicating that the phenological expression in the opening month of erratic rain period in the region is a perpetuation strategy from the analyzed species. We concluded that, in herborized botanical materials, it is possible to assess responses to climatic conditions in the Amazon.
\end{abstract}

Keywords: Amazon; Flowering; Rainfall.

Muller Silva Pimentel

Universidade do Estado do Pará, Brasil http://lattes.cnpq.br/0741859035402453 muller pimentel@yahoo.com.br

Lucieta Guerreiro Martorano (iD) Embrapa Amazônia Oriental, Brasil http://lattes.cnpq.br/9712490260615310 http://orcid.org/0000-0003-3893-3781 martorano.lucietta@gmail.com

Ana Cláudia Caldeira Tavares Martins (iD Universidade do Estado do Pará, Brasil http://lattes.cnpq.br/6547250062275801 http://orcid.org/0000-0003-4972-036X lucieta.martorano@embrapa.br

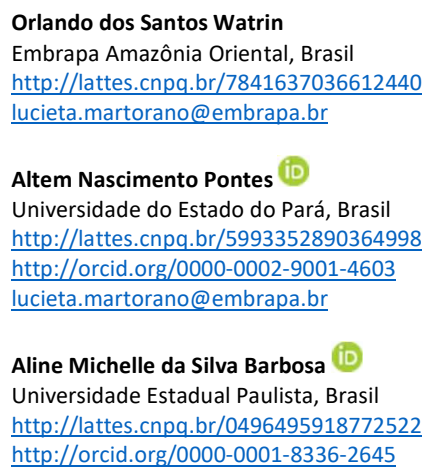

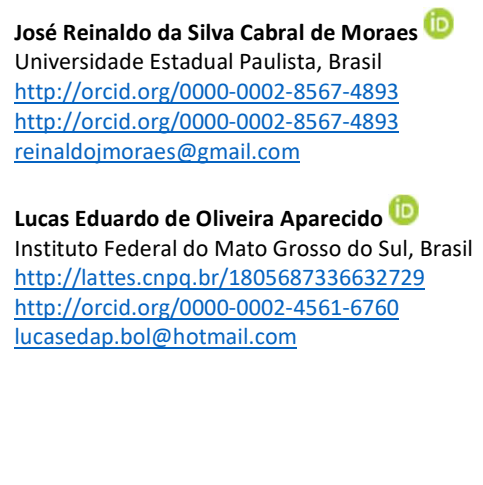

6

DOI: 10.6008/CBPC2179-6858.2018.005.0005
Referencing this:

PIMENTEL, M. S.; MARTORANO, L. G.; MARTINS, A. C. C. T.; WATRIN, O. S.; PONTES, A. N.; BARBOSA, A. M. S.; MORAES, J. R. S. C.; APARECIDO, L. E. O.. Expressões fenológicas de palmeiras em coleções botânicas associadas às condições pluviais na Floresta Tapajós. Revista Ibero Americana de Ciências Ambientais, v.9, n.5, p.39-50, 2018. DOI: http://doi.org/10.6008/CBPC2179-6858.2018.005.0005 


\section{INTRODUÇÃO}

A família Arecaceae, representada pelas palmeiras, apresenta distribuição expressiva no mundo, abrangendo cerca de 200 gêneros e 1.500 espécies (HENDERSON et al., 1997). No continente Americano, apenas para a América do Sul são registradas 459 espécies, distribuídas em 50 gêneros (PINTAUD et al., 2008). Na Amazônia, as palmeiras estão associadas à família botânica de maior hiperdominância (STEEGE et al., 2013), compreendendo 147 distintas espécies (LEITMAN et al., 2015). Dessa forma, as palmeiras podem ser estudadas na compreensão de áreas em via de sucessão ecológica em vários ambientes, devido à dominância populacional (GAMA et al., 2002; SILVA, 2008) e possíveis respostas às pressões antrópicas. Tal característica revela também, a importância desses vegetais, dentre outros fatores, para a manutenção de cadeias tróficas em diversos ecossistemas (MIRANDA et al., 2001).

Como bem oriundo da floresta nativa, muitas espécies de palmeiras amazônicas são fontes de alimento, abrigo, ornamentação e produtos na medicina tradicional (NASCIMENTO et al., 2014). Diante da diversidade de espécies, do alto potencial de uso e da capacidade de permanência em ambientes alterados, surge a necessidade de se ampliar as informações fenológicas das palmeiras, uma vez que, a fenologia responde aos aspectos biológicos ligados a fatores bióticos e abióticos presentes em uma determinada área (TALORA et al., 2000).

Segundo Bianchini et al. (2006), o padrão de distribuição das palmeiras está relacionado ao processo fenológico em decorrência do clima, por exemplo, expressando crescimento, desenvolvimento e rendimento em função de fatores como estresse térmico-hídrico, fotoperíodo, radiação solar e vento. Estudos como de Rosa et al. (1998) e Mantovani et al. (2000) sugerem que a fenologia de palmeiras promovem padrões distintos a partir de dados climáticos em diferentes regiões do Brasil. Dentre os dados climáticos mais impactantes na resposta fenológica de espécies vegetais na Amazônia, a precipitação pluvial é a variável que tem sido mais discutida, pois grande parte da região não apresenta amplitude térmica considerável. Martorano et al. (1992) e Almeida et al. (2010) destacam que nos estudos que se façam necessário o uso desta variável, há necessidade que a análise seja feita considerando séries históricas relativamente longas para que haja maior confiabilidade nos dados, pois trata-se de uma interpretação que está associada à eventos tantos naturais quanto antropogênicos.

As pesquisas sobre o período reprodutivo auxiliam nas avaliações da dinâmica de populações, inclusive sobrevivência, frente aos aspectos fenológicos, em especial, o de floração (MANTOVANI et al., 2003). Nesse sentido, as coleções botânicas consistem em ótimos repositórios de dados e informações para análise, já que documentam a diversidade biológica, além de que os espécimes depositados, sob a forma de exsicatas, guardam parte da história das áreas levantadas, indicando, por exemplo, qual era a cobertura vegetal natural de área atualmente já desflorestada (PEIXOTO et al., 1989; SOUZA et al., 2013). Nos herbários são encontradas informações botânicas importantes capazes de subsidiar avaliações de plantas com valor comercial e ambiental, além de auxiliar nas análises de perdas por desmatamento em áreas tropicais. Maués et al. (2002) e Ruiz et al. (2004) observaram padrões fenológicos relacionados a dados meteorológicos, entre 
eles a precipitação pluvial, para a avaliação da floração e da frutificação de espécies na Amazônia, analisando como as estações seca e chuvosa influenciam no aparecimento de cada fenofase.

Kahn et al. (1992) destacam que as palmeiras apresentam floração e frutificação em períodos distintos em vários ecossistemas na Amazônia, tendo por análise fundamental a estação seca e a chuvosa. Para esses autores, há poucas observações registradas sobre processos fenológicos aliados ao regime de precipitação pluvial no bioma em questão. Considerando essas premissas, foram estabelecidas as seguintes questões norteadoras: Os herbários possuem dados capazes de mostrar expressões fenológicas em palmeiras na área de estudo? Dados pluviais de séries históricas mensais podem subsidiar avaliações de respostas fenológicas a partir de dados contidos nas exsicatas? Os dados de herbários associadas aos dados pluviais ampliam as possibilidades de análises temporais e fortalecem a importância das bases de dados botânicos na identificação de perda da biodiversidade florística em condições climáticas atuais e em cenários de mudanças futuras?. Dessa forma, define-se o objetivo deste trabalho que seria avaliar como os registros em herbários, em particular, expressões fenológicas de espécies da família Arecaceae, podem ser associadas às condições de precipitação pluvial na área correspondente a Flona Tapajós e seu entorno, no estado do Pará.

\section{MATERIAIS E MÉTODOS}

A área de estudo corresponde à Floresta Nacional do Tapajós e ao entorno de $30 \mathrm{~km}$ de sua borda, localizada no oeste estado do Pará, nos municípios de Aveiro, Belterra, Placas, Rurópolis e Santarém (Figura 1). Com aproximadamente $19.670 \mathrm{~km}^{2}$, a área é drenada pelo Rio Tapajós e por igarapés tributários, sendo a malha viária existente subordinada à rodovia BR-163.

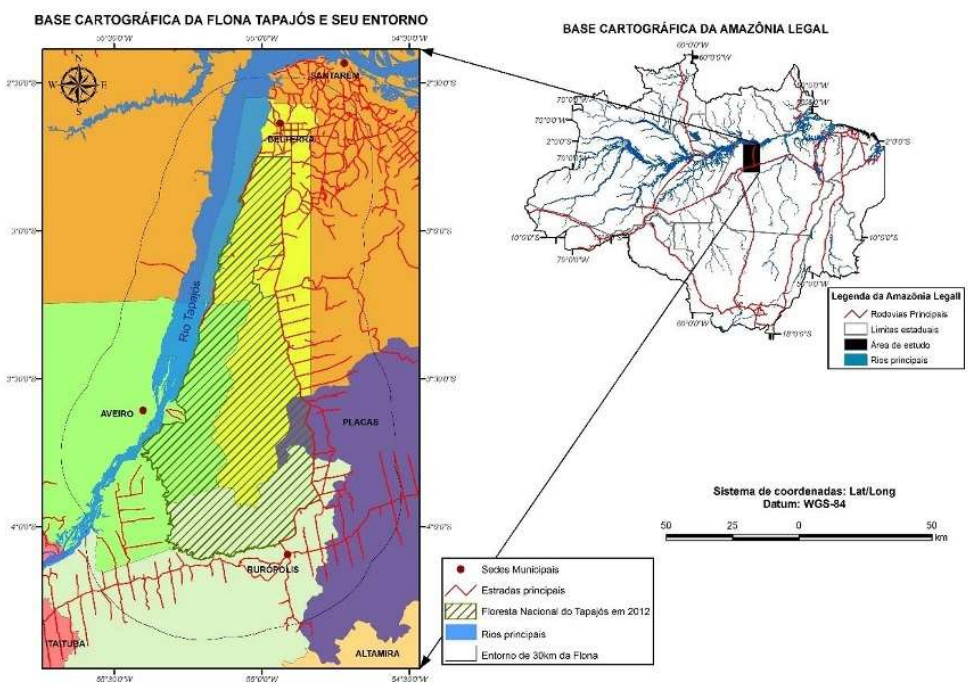

Figura 1: Localização da área de estudo. Fonte: Lisboa (2015).

O levantamento dos dados em coleções botânicas foi desenvolvido nos herbários da Embrapa Amazônia Oriental (IAN/ EMBRAPA) e do Museu Paraense Emílio Goeldi (MPEG/ João Murça Pires), ambos localizados em Belém, Pará. No período de dezembro de 2013 e janeiro de 2014, foram examinadas exsicatas 
férteis (com flores e/ou frutos) da família Arecaceae referentes às coleções botânicas oriundas da área da Floresta Nacional do Tapajós e seu entorno.

A partir da ficha de identificação das exsicatas foram compilados dados de coleta e seus respectivos ambientes em planilhas eletrônicas (Microsoft Excel), possibilitando a quantificação dos registros e a definição do percentual de ocorrência das espécies e gêneros dominantes. Foram consideradas observações como: coletor, nome científico, número da amostra, revisor, data da revisão, número de registro, herbário, local da coleta, data da coleta, coordenadas geográficas, nome popular e características morfológicas.

Para identificar espacialmente o local de coleta das amostras botânicas herborizadas, optou-se pelo uso de ferramentas espaciais: Tageo (Geography Population Map Cities Coordinates), Google Maps e Google Earth, adotando-se o município mais próximo do local da coleta, no presente caso, Rurópolis ou Santarém. A confirmação e a atualização dos nomes científicos das espécies levantadas foi realizada com base em Leitman et al. (2015), além de consulta nos portais Species Link e W3 Tropicos. Para a revisão do gênero Bactris, em adição as referências anteriores, foi utilizado Henderson (2000).

A análise exploratória dos dados associou a ocorrência das espécies com a precipitação pluvial de séries históricas a partir dos dados disponibilizados pelo Instituto Nacional de Meteorologia (INMET) e pelo National Centers for Environmental Prediction (NCEP), correspondentes aos municípios de Belterra e Santarém. Os dados pluviais referentes ao município de Rurópolis foram disponibilizados pela Agência Nacional de Águas (ANA). Os períodos analisados para Belterra e Santarém foram de 1972-2012 e 1979-2009, respectivamente, sendo utilizados também para Rurópolis para ampliar a base de dados de avaliação, pois os dados pluviais no período homogêneo seguiu o mesmo padrão de variação. Como existe limitação de longas séries de dados pluviais na área de estudo, manteve-se na base de avaliação também os dados de Rurópolis.

Nesses períodos, os dados observados foram utilizados para verificar a precipitação pluvial na Flona Tapajós e nos municípios do seu entorno, considerando-se o registro do mês e ano contido nas exsicatas selecionadas. A precipitação pluvial mensal foi obtida contabilizando os totais de chuva no mês, bem como também foram contabilizados os totais nos dois meses anteriores para melhor compreensão dos processos fenológicos de floração e de frutificação associados à oferta pluvial no trimestre até a data no material registrado nos herbários.

\section{RESULTADOS}

Tabela 1: Espécies da família Arecaceae registradas em coleções botânicas para os municípios de Belterra, Rurópolis e Santarém, Pará.

\begin{tabular}{|l|l|l|l|l|l|}
\hline & & \multicolumn{2}{|l|}{ IAN/Embrapa } & MPEG \\
\hline Espécie & Nome popular & Belterra & Santarém & Rurópolis & Santarém \\
\hline Attalea spectabilis Mart. & curuá & $\mathrm{x}$ & $\mathrm{x}$ & - & - \\
\hline Astrocaryum aculeatum G. Mey. & tucumã & - & - & $\mathrm{x}$ & - \\
\hline Astrocaryum gynacanthum Mart. & mumbaca & - & - & $\mathrm{x}$ & $\mathrm{x}$ \\
\hline Attalea maripa (Aubl.) Mart. & inajá & - & - & $\mathrm{x}$ & - \\
\hline Bactris acanthocarpa Mart. & marajá & - & $\mathrm{x}$ & - & - \\
\hline Bactris acanthocarpoides Barb. Rodr. & marajá & - & - & $\mathrm{x}$ & - \\
\hline Bactris campestris Poepp. ex Mart. & marajá & - & $\mathrm{x}$ & - & - \\
\hline
\end{tabular}




\begin{tabular}{|c|c|c|c|c|c|}
\hline Bactris elegans Barb. Rodr. & marajá & - & - & - & $x$ \\
\hline Bactris gastoniana Barb. Rodr. & marajá & - & - & - & $\mathrm{x}$ \\
\hline Bactris hirta Mart. & marajá & - & $\mathrm{x}$ & - & - \\
\hline Bactris maraja Mart. & marajá & - & - & - & $\mathrm{x}$ \\
\hline Bactris oligocarpa Barb. Rodr. \& Trail & marajá & & & - & $\mathrm{x}$ \\
\hline Bactris simplicifrons Mart. & marajá & - & $\mathrm{x}$ & - & $\mathrm{x}$ \\
\hline Desmoncus mitis Mart. & jacitara & - & - & - & $\mathrm{x}$ \\
\hline Desmoncus polyacanthos Mart. & jacitara & - & $x$ & $\mathrm{x}$ & - \\
\hline Geonoma deversa (Poit.) Kunth & ubim & $\mathrm{x}$ & - & - & $\mathrm{x}$ \\
\hline Geonoma leptospadix Trail & ubim & - & - & - & $\mathrm{x}$ \\
\hline Geonoma macrostachys Mart. & ubim & - & - & $x$ & $\mathrm{x}$ \\
\hline Geonoma maxima (Poit.) Kunth & ubim & $\mathrm{x}$ & $x$ & - & $x$ \\
\hline Geonoma poiteauana Kunth & ubim & - & - & $\mathrm{x}$ & - \\
\hline Geonoma stricta (Poit.) Kunth & ubim & - & - & - & $\mathrm{x}$ \\
\hline Iriartella setigera (Mart.) H.Wendl. & paxiubinha & $x$ & - & - & $\mathrm{x}$ \\
\hline Leopoldinia pulchra Mart. & jará & $\mathrm{x}$ & $x$ & - & $\mathrm{x}$ \\
\hline Lepidocaryum tenue Mart. & caranaí & - & - & - & $\mathrm{x}$ \\
\hline Mauritia flexuosa L.f. & buriti & - & - & $\mathrm{x}$ & - \\
\hline Oenocarpus bacaba Mart. & bacaba & - & - & - & $\mathrm{x}$ \\
\hline Oenocarpus bataua Mart. & patauá & - & - & - & $\mathrm{x}$ \\
\hline Oenocarpus distichus Mart. & bacaba-de-leque & - & - & $\mathrm{x}$ & - \\
\hline Oenocarpus minor Mart. & bacabinha & - & $\mathrm{x}$ & - & - \\
\hline Socratea exorrhiza (Mart.) H. Wendl. & paxiúba & - & - & $\mathrm{x}$ & - \\
\hline Syagrus cocoides Mart. & jatá & $\mathrm{x}$ & $\mathrm{x}$ & $x$ & - \\
\hline Syagrus comosa (Mart.) Mart. & catolé & - & - & $\mathrm{x}$ & - \\
\hline Syagrus petraea (Mart.) Becc. & arirí & - & - & $\mathrm{x}$ & - \\
\hline Syagrus inajai (Spruce) Becc. & pupunharana & - & - & - & $\mathrm{x}$ \\
\hline
\end{tabular}

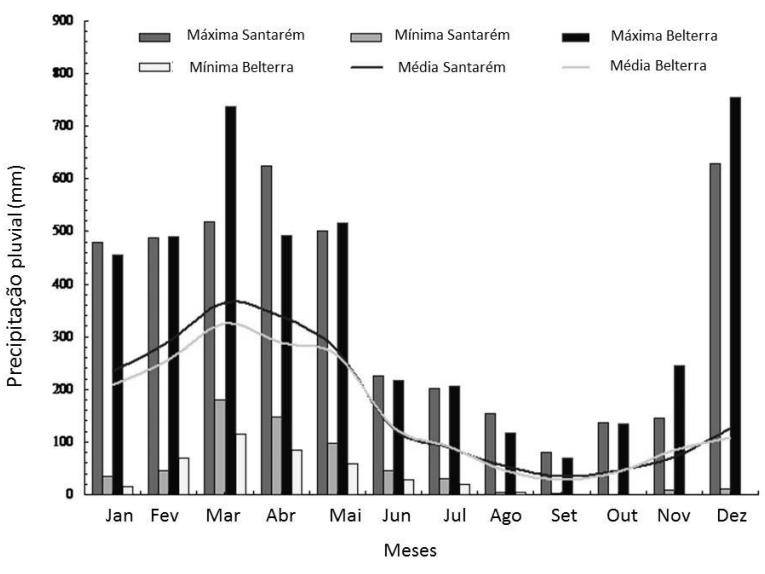

Figura 2: Distribuição média mensal da precipitação pluvial nas estações meteorológicas de Belterra e Santarém (1979 e 2009), Pará. Fonte: Dados INMET - Série Histórica (1979 a 2009).

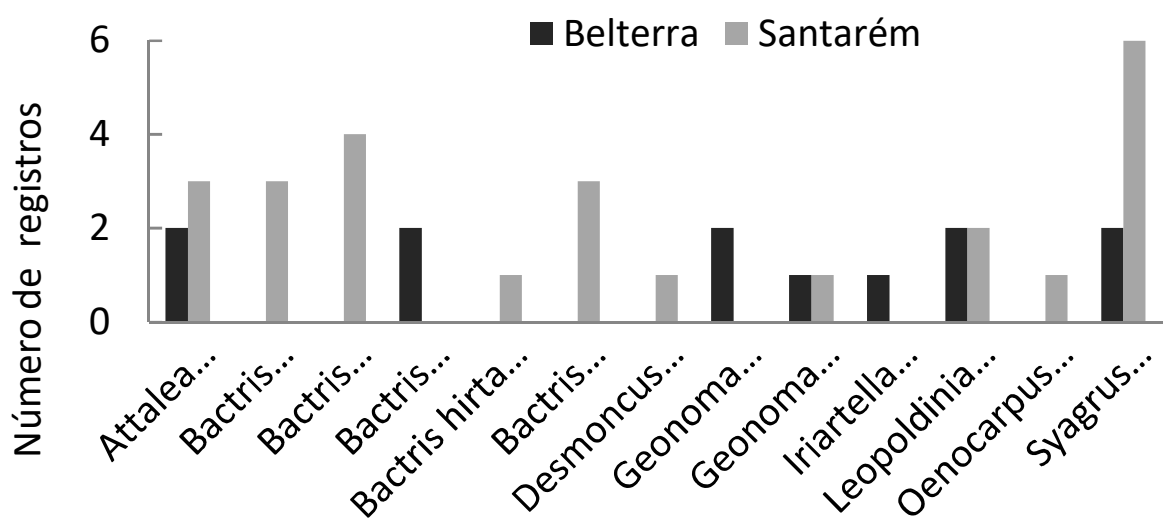

\section{Espécies da Família Arecaceae}

Figura 3: Número de registros para cada espécie catalogada no herbário IAN/EMBRAPA, nos municípios do entorno da Flona Tapajós, Pará. 
Tabela 2: Número de registros e percentagem de espécies em Santarém, Pará, no herbário IAN/EMBRAPA, com destaque para os gêneros Bactris e Syagrus.

\begin{tabular}{|l|l|l|l|}
\hline Espécies & Nome popular & No de registros & $\%$ \\
\hline Attalea spectabilis Mart. & Curuá & 3 & 12 \\
\hline Bactris acanthocarpa Mart. & Marajá & 3 & 12 \\
\hline Bactris campestres Poepp. Ex Mart & Marajá & 16 \\
\hline Bactris hirta Mart. & Marajá & 4 \\
\hline Bactris simplicifrons Mart. & Marajá & 1 & 12 \\
\hline Desmoncus polyacanthos Mart & Jacitara & 1 & 4 \\
\hline Geonoma máxima (poit.) Kunth & Ubim & 4 \\
\hline Leopoldina pulchra Mart. & Jará & 1 & 8 \\
\hline Oenocarpus minor mart. & Bacabinha & 4 \\
\hline Syagrus cocoides Mart. & Jatá & 1 \\
\hline Total & & 6 & 24 \\
\hline
\end{tabular}

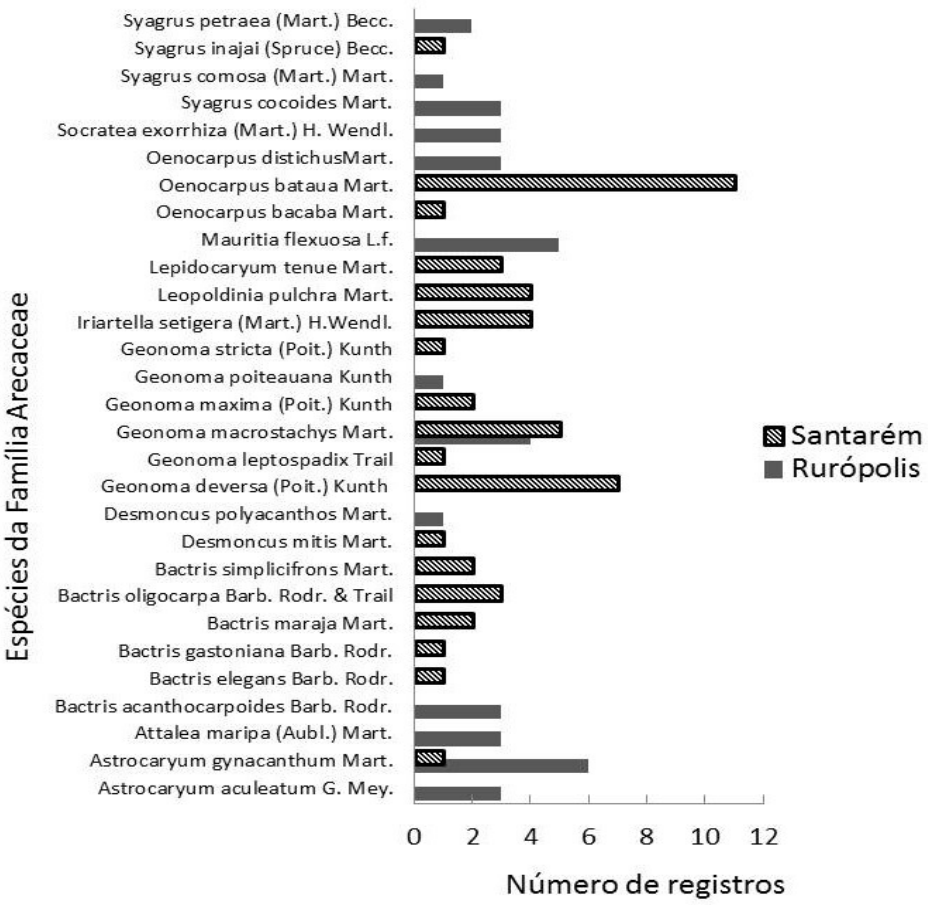

Figura 4: Número de registros para cada espécie catalogada no herbário MPEG nos municípios do entorno da Flona Tapajós, PA.

Tabela 3: Número de registros e percentagem de espécies em Santarém, Pará, no herbário MPEG, com destaque para as espécies dos gêneros Bactris, Geonoma e Oenocarpus.

\begin{tabular}{|l|l|l|l|}
\hline Espécie & Nome Popular & № de ocorrência & $\%$ \\
\hline Bactris elegans Barb. Rodr. & marajá & 1 & 2,2 \\
\hline Bactris gastoniana Barb. Rodr. & marajá & 1 & 2,2 \\
\hline Bactris maraja Mart. & marajá & 2 & 4,4 \\
\hline Bactris oligocarpa Barb. Rodr. \& Trail & marajá & 6,7 \\
\hline Bactris simplicifrons Mart. & marajá & 3 & 4,4 \\
\hline Geonoma deversa (Poit.) Kunth & ubim & 2 & 15,6 \\
\hline Geonoma leptospadix trail & ubim & 7 & 2,2 \\
\hline Geonoma máxima (Poit.) Kunth & ubim & 1 & 4,4 \\
\hline Geonoma stricta (Poit.) Kunth & ubim & 2,2 \\
\hline Desmoncus mitis Mart. & jacitara & 2,2 \\
\hline Iriartella setigera (Mart.) H.Wendl. & paxiubinha & 9,0 \\
\hline Leopoldinia pulchra Mart. & jará & 1 & 9,0 \\
\hline Lepidocaryum tenue Mart. & caranaí & 1 & 6,7 \\
\hline Oenocarpus bacaba Mart. & bacaba & 4 & 2,2 \\
\hline Oenocarpus bataua Mart. & patauá & 4 & 24,4 \\
\hline Syagrus inajai (Spruce) Becc. & pupunharana & 3 & 2,2 \\
\hline Total & & 1 & 100 \\
\hline
\end{tabular}




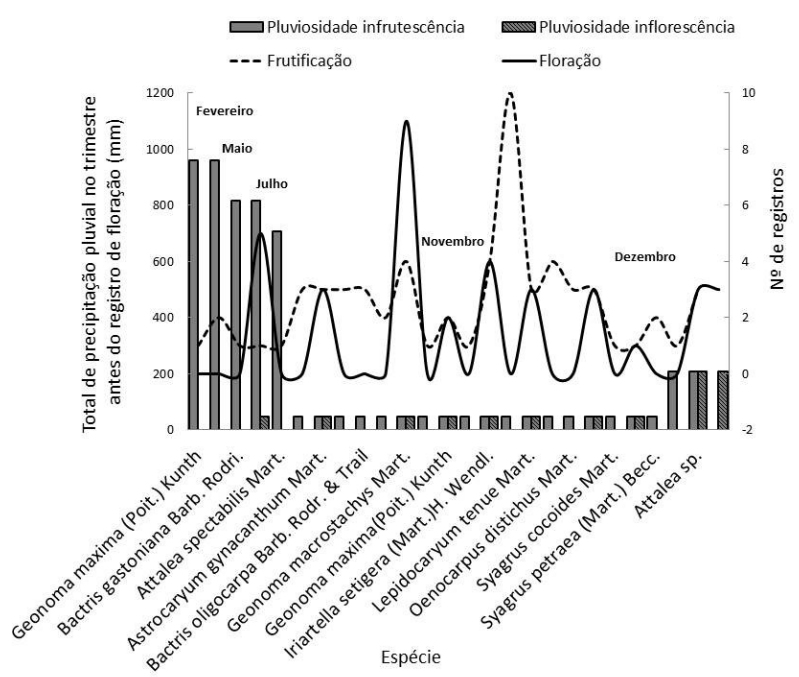

Figura 5: Análise das fenofases de floração e frutificação com base no número de registros das espécies da família

Arecaceae nos herbários IAN/EMBRAPA e MPEG, relacionadas à precipitação pluvial trimestral.

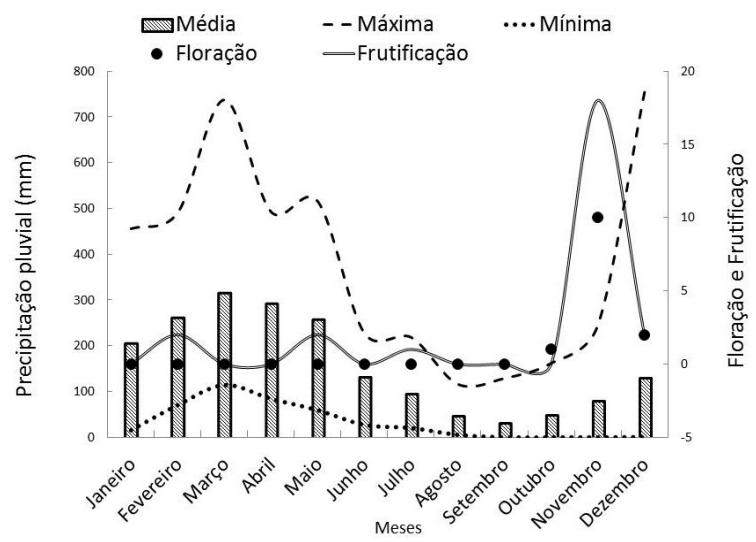

Figura 6: Média, máxima e mínima da precipitação pluvial com base nos registros das exsicatas com floração e frutificação nos herbários IAN/EMBRAPA e MPEG.

\section{DISCUSSÃO}

O regime de precipitação pluvial mensal em Belterra e Santarém (Figura 2) evidenciou que o mês mais chuvoso é março, com médias de 364,1 mm em Santarém e 325,9 mm em Belterra. Em termos de eventos extremos máximos, foi contabilizado em Belterra $737,1 \mathrm{~mm}$ no mês de março de 2008 , enquanto em Santarém, os maiores valores de precipitação pluvial foram no mês de abril, totalizando $623,9 \mathrm{~mm}$. No período de janeiro a maio existe nítida variação na distribuição das chuvas nas duas localidades estudadas. Por outro lado, de junho a dezembro os valores ficam bem próximos, sendo as linhas de precipitação pluvial praticamente coincidentes, indicando que nesse período o regime de chuva possui praticamente efeitos de sistemas locais, dada a baixa flutuação nos eventos pluviais que são contabilizados nessa época do ano, considerado como o verão Amazônico. Setembro é o mês menos chuvoso tanto em Santarém quanto em Belterra com médias de $28,6 \mathrm{~mm}$. Nos registros dos herbários, foram encontradas 34 espécies da família Arecaceae, sendo que no herbário do IAN/EMBRAPA registrou-se 13 espécies, enquanto no Museu Paraense Emílio Goeldi - MPGE, foram encontradas 29 espécies (Tabela 1).

No herbário IAN/EMBRAPA, das 13 espécies de palmeiras registradas, S. cocoides e $B$. campestris foram as mais frequentes (Figura 3). Verificou-se que o número de espécies do gênero Bactris foi maior que o observado para outros gêneros, enquanto a espécie Syagrus cocoides Mart. foi a que apresentou o maior número de registros, destacados na Tabela 2. Já no herbário MPEG, das 29 espécies de palmeiras registradas, A. gynacanthum, G. deversa, G. macrostachys e O. bataua foram as espécies de maior ocorrência (Figura 4). Os gêneros Bactris, Geonoma e Oenocarpus registrados nas exsicatas do herbário MPEG, em Santarém, predominaram em relação aos outros gêneros presentes no referido herbário. Bactris e Geonoma foram relevantes pela quantidade de espécies, enquanto Oenocarpus apresentou alto número de registros da espécie Oenocarpus bataua Mart. (Patauá) (Tabela 3). 
O mês de novembro foi o que apresentou o maior número de registros de espécies e de indivíduos em floração e frutificação. De todas as espécies registradas, Geonoma macrostachys Mart. e Oenocarpus bataua Mart. apresentaram os maiores registros de floração e frutificação para o mês de novembro, com nove e dez ocorrências, respectivamente. Esses registros em novembro, tanto para G. macrostachys quanto para 0 . bataua podem expressar efeitos da reduzida pluviosidade média do trimestre que contabilizou 48,4 $\mathrm{mm}$ (Figura 5).

A análise exploratória de dados revelou diferentes registros de floração e frutificação contidos nas exsicatas dos herbários IAN/EMBRAPA e MPEG, baseando-se na média, máxima e mínima da precipitação pluvial dos meses de fevereiro, maio, julho, outubro, novembro e dezembro. Os dados de precipitação pluvial no mês de novembro contabilizaram valores médios de 79,6 mm, máxima de $244,6 \mathrm{~mm}$ e anos sem registros pluviais nesse mês. No mês de dezembro, ainda com oferta pluvial reduzida, os números de registros botânicos com floração e frutificação foram bem expressivos, obtendo-se 10 registros de floração, enquanto que para a frutificação, foram contabilizados 18 registros (Figura 6). Este comportamento evidencia que no final do período de menor oferta pluvial na região, as chuvas contabilizadas entre outubro e dezembro podem estar associadas às expressões de floração e de frutificação documentadas nos levantamentos florísticos presentes nos registros de ambos os herbários analisados.

Verificou-se que do total de 34 espécies registradas neste levantamento, as cinco espécies com o maior número de registros são representadas por $A$. aculeatum, A. gynacanthum, A. spectabilis, $B$. acanthocarpoides e B. campestres. Em um estudo realizado com comunidades de palmeiras na Amazônia Central por Henderson et al. (2000), foram registradas 31 espécies, das quais 12 pertenciam ao gênero Bactris, quatro ao gênero Geonoma e três ao gênero Oenocarpus, sendo que esses três gêneros apresentaram as maiores ocorrências. Neste trabalho, ao comparar os registros de ocorrência desses três gêneros, observou-se que a floração e a frutificação para esses gêneros estavam associadas ao período de redução das chuvas e aos registros em novembro, evidenciando a expressão das fenofases, nesse mês em que os eventos pluviais tornam a ocorrer na região.

Henderson et al. (2000) verificaram que algumas espécies do gênero Bactris e a espécie Geonoma maxima var. sprucena floresceram no período chuvoso e no período seco, respectivamente. Em particular para Bactris, devido a sua diversidade, Listabarth (1996) ressaltou a partir da biologia reprodutiva de espécies do gênero que houve floração tanto no período chuvoso quanto no período seco, citando que em curtos períodos de tempo as palmeiras estavam sem flor. Então, infere-se que o gênero Bactris pode apresentar um longo período para floração seguido de um tempo mais curto para frutificação. Na avaliação do presente trabalho as espécies B. gastoniana, B. acanthocarpoides e $B$. oligocarpa estão registradas com frutos, sendo que a primeira para a estação mais chuvosa, enquanto as duas últimas para a estação menos chuvosa. Para O. bataua Mart., notou-se que os registros identificados predominam nas imediações da rodovia BR-163. A baixa precipitação no mês de novembro e os registros de frutificação evidenciam que para expressar essa fenofase as plantas necessitam de um período de escassez de chuva. 
De acordo com Núñez (2008), nos Andes Colombianos foram observados 624 indivíduos de O. bataua Mart. amostrados, 220 floresceram o ano todo, com um pico entre os meses de dezembro e fevereiro, sendo a menor precipitação de agosto de 2005 a julho de 2006 e a frutificação ocorreu no período mais chuvoso, de março a novembro. Para a área correspondente a reserva florestal Adolpho Ducke, Manaus, Ruiz et al. (2004) verificaram que os frutos maduros de $O$. bataua ocorriam em maior quantidade no mês de novembro, chegando a um valor máximo em maio, término do período chuvoso na região, considerando uma série histórica de agosto de 1978 a dezembro de 1994.

Dessa forma, observa-se que mesmo para regiões diferentes, o estudo de Ruiz et al. (2004) apontou resultados semelhantes ao trabalho de Núñez (2008) em relação à definição da frutificação no período mais chuvoso. Entretanto, tais constatações divergem com os dados obtidos neste estudo que observou maior frutificação para a espécie relacionada ao período de menor precipitação mensal (novembro). Isso possivelmente pode ser explicado pela localidade avaliada apresentar condições bióticas e outros fatores abióticos que favoreçam a frutificação. Com base nos registros dos dois herbários analisados, observou-se que houve ocorrência de diferentes espécies do gênero Bactris no planalto de Santarém, Belterra, reforçando possíveis respostas das palmeiras às condições edafoclimáticas da região de estudo.

Outro aspecto que deve ser destacado é que os dados de herbários são condicionados ao período, frequência de coletas, especificidade tanto ao método de coleta, morfologia das espécies e preparação do material biológico para herborização. Também, Núñez et al. (2015) destacaram que as palmeiras possuem limitação de registros botânicos. Sabe-se que tradicionalmente esse grupo de plantas tem sido excluído de inventários florestais para fins madeireiros e em estudos de regeneração de espécies nativas da Amazônia. Neste estudo, os registros de frutificação foram maiores no período com baixa oferta pluvial (Figura 6). Tais registros podem indicar que certas palmeiras, em especial as espécies registradas para novembro ( $A$. aculeatum, A. gynacanthum, B. acanthocarpoides, B. oligocarpa, Euterpe sp., G. macrostachys, G. leptospadix, G. maxima, G. stricta, I. setigera, O.bataua, L. tenue, M. flexuosa, O. distichus, S. exorrhiza, S. cocoides, S. inajai e S. petraea) emitem suas inflorescências em um período menos chuvoso, aproveitando ao máximo a radiação solar para a produção de suas infrutescências.

Martínez Ramos et al. (2009) sugerem que a estrutura demográfica das palmeiras de florestas tropicais pode ser fortemente alterada por perturbações episódicas naturais como, por exemplo, o El Niño, influenciando em seu ciclo reprodutivo, reforçando os efeitos provenientes da redução na oferta pluvial, em anos com essa anomalia climática. Almeida et al. (2010) destacam que em anos com chuvas sazonais e com período chuvoso não bem definido em uma determinada localidade, dificultam a interpretação das análises integradas planta-ambiência. No caso da Flona Tapajós, tem-se observado aumento nas atividades antrópicas (SOUZA FILHO et al., 2012), o que potencializa a redução da população de algumas espécies de palmeiras. Além disso, as respostas aos eventos climáticos de médio e grande escala que influenciam no regime pluvial podem estar comprometendo a fenologia de palmeiras na área de estudo. 
No presente estudo, os registros mais frequentes de espécies em floração ocorreram no mês de novembro, sendo nove para G. macrostachys, quatro para I. setigera, três para A. gynacanthum, três para $L$. tenue, três para S. exorrhiza, dois para G. maxima e um para S. inajai. As ocorrências de floração nos demais meses foram reduzidas, sendo observadas cinco para G.deversa em maio, três para Attalea sp. e três para $L$. pulchra, em dezembro (Figura 6). A reprodução observado por Oliveira et al. (2003) para uma população de Astrocaryum vulgare Mart. (Tucumã), em Belém, Pará, observou registros de floração e frutificação no período chuvoso, sendo que para a frutificação, mais de $50 \%$ das plantas estavam com frutos maduros.

Em se tratando do gênero Geonoma, em especial para a G. macrostachys Mart., o alto número de registros para floração em Rurópolis e Santarém reflete o número e frequência de coleta. A série histórica da precipitação pluvial para a área de estudo indica que para o trimestre menos chuvoso os maiores registros de floração e frutificação foram para G. macrostachys e $O$. bataua. Os dados apontam ainda que a redução das chuvas desencadeou estresses hídricos às plantas, induzindo processos fenológicos diferenciados (Figura 7). Arasato et al. (2013) associando dados de precipitação e ocorrência de palmeiras, notaram que a quantidade de precipitação no mês de novembro foi mais relevante do que outras variáveis ambientais com relação a distribuição de palmeiras na Amazônia Legal.

Alencar (1994) observou que espécies arbóreas da família Sapotaceae, na Reserva Ducke, Manaus, apresentaram floração correlacionadas positivamente com a estação seca e a frutificação correlacionada com a estação chuvosa. Entretanto, foi ressaltado que as análises focando em variáveis climáticas não são suficientes para explicar a reprodução de espécies botânicas, as quais também são influenciadas por outras condicionantes ecológicas e também endógenas.

Ainda no contexto das avaliações associadas os efeitos quanto a oferta hídrica no solo, a precipitação pluvial é uma variável indutora de propagação das palmeiras. Outra variável biofísica que influencia na distribuição de palmeiras é a topografia e características edáficas, segundo Vormisto et al. (2004) e Eiserhardt et al. (2011) auxiliam no entendimento da dinâmica de populações, influenciando na reprodução das plantas e nas respostas fisiológicas. Os resultados obtidos nesta pesquisa evidenciaram que os registros contidos em materiais botânicos herborizados auxiliam na interpretação de informações fenológicas sobre palmeiras, a partir do fornecimento de descrições botânicas e ambientais que possibilitam associá-los a dados climáticos de séries temporais na Amazônia. Os dados disponíveis nos herbários ampliam as possibilidades de análises de séries temporais de clima, possibilitando avaliar respostas da biodiversidade florística sob condições atuais e em cenários de mudanças climáticas.

\section{CONCLUSÕES}

A partir dos resultados concluiu-se que das 34 espécies da família Arecaceae registradas nos dois herbários analisados, o maior número de registros concentrou-se no herbário do MPEG, enquanto as maiores ocorrências na região de estudo se concentraram no município de Santarém. Dentre os espécimes herborizados, houve dominância dos gêneros Bactris, Geonoma e Oenocarpus, sendo Syagrus cocoides Mart. 
(jatá) e Oenocarpus bataua Mart. (patauá) as espécies com o maior número de registros no herbário IAN/EMBRAPA e MPEG, respectivamente.

Observou-se que muitos registros de floração e/ou frutificação ocorreram no mês de novembro, sendo este associado ao trimestre mais seco na área de estudo. Os resultados evidenciaram que os registros contidos em materiais botânicos herborizados auxiliam na interpretação de informações fenológicas sobre palmeiras, possibilitando associá-los a dados climáticos de séries temporais na Amazônia.

\section{REFERÊNCIAS}

ALENCAR, J. C.. Fenologia de cinco espécies arbóreas tropicais de Sapotaceae correlacionada a variáveis climáticas na Reserva Ducke, Manaus - AM. Acta Amazonica, Manaus, v.24, n.3, p.161-182, 1994

ALMEIDA, R.; REBELLO, E.; AMBRIZZI, T.. Variabilidade de eventos extremos e identificação de tendências climáticas no litoral norte do Brasil. In: CONGRESSO BRASILEIRO DE METEOROLOGIA, 16. Anais. Belém: CBMET, 2010.

ARASATO, L. S.; AMARAL, S.. Geoprocessamento e biodiversidade: contribuições para a modelagem da distribuição de palmeiras amazônicas. In: SIMPÓSIO BRASILEIRO DE SENSORIAMENTO REMOTO, 16. Anais. São José dos Campos: INPE, 2013. p.6767-6774.

BIANCHINI, E.; PIMENTA, J. A.; SANTOS, F. A. M.. Fenologia de Chrysophyllum gonocarpum (Mart. \& Eichler) Engl. (Sapotaceae) em floresta semidecídua do sul do Brasil. Revista Brasileira de Botânica, São Paulo, v.29, n.4, p.595602, 2006.

EISERHARDT, W. L.; SVENNING, J. C.; KISSLING, W. D.; BALSLEV, H.. Geographical ecology of the palms (Arecaceae): determinants of diversity and distributions across spatial scales. Annals of Botany, Oxford, v.108, n.8, p.1391-1416, 2011.

GAMA, J. R. V.; BOTELHO, S. A.; GAMA-BENTES, M. M. Composição florística e estrutural da regeneração natural de floresta secundária de várzea baixa no estuário amazônico. Revista Árvore, Viçosa, v.26, n.5, p.559-566, 2002.

HENDERSON, A.. Flora Neotropica: Monograph 79. New York: The New York Botanical Garden, 2000.

HENDERSON, A.; FISCHER, B.; SCARIOT, A. PACHECO, M. A. W.; PARDINI, E.. Flowering of a palm community in a central Amazon forest. Brittonia, New York, v.52, n.2, p.149-159, 2000.

HENDERSON, A.; GALEANO, G.; BERNAL, R.. Field guide to the palms of the Americas. Princeton: Princeton University Press, 1997.

KAHN, F.; GRANVILLE, J. J.. Palms in forest ecosystems of Amazonia. Berlin: Springer-Verlang, 1992.

LEITMAN, P.; SOARES, K.; HENDERSON, A.; NOBLICK, L.; MARTINS, R. C.. Arecaceae. In: LEITMAN, P.; SOARES, K.; HENDERSON, A.; NOBLICK, L.; MARTINS, R. C.. Lista de espécies da flora do Brasil. Jardim Botânico do Rio de Janeiro. 2015.

LISTABARTH, C.. Pollination of Bactris by Phyllotrox and Epurea. Implications of the palm Breeding Beetles on Pollination at the community level. Biotropica, Malden, v.28, n.1, p.69-81, 1996

MANTOVANI, A.; MORELLATO, L. P. C.. Fenologia da floração, frutificação, mudança foliar e aspectos da biologia floral do palmiteiro Euterpe edulis (Arecaceae). Sellowia, Itajaí, v.4952, p.23-38, 2000 .

MANTOVANI, M.; RUSCHEL, A. R.; REIS, M. S.; PUCHALSKII, A.; NODARI, R. O.. Fenologia reprodutiva de espécies arbóreas em uma formação secundária da floresta atlântica. Revista Árvore, Viçosa, v.27, n.4, p.451-458, 2003.

MARTÍNEZ-RAMOS, M.; ANTEN, M. P. R.; ACKERLY, D. D. Defoliation and ENSO effects on vital rates of an understory tropical rain forest palm. Journal of Ecology, London, v.97, p.1050-1061, 2009.

MARTORANO, L. G.; PEREIRA, L. C.; COSTA, A. C. L.; RIBEIRO J. T.. Variabilidade da precipitação pluviométrica em Belém Pará associada ao fenômeno El Niño. In: CONGRESSO BRASILEIRO DE METEOROLOGIA, 7. Anais. São Paulo: SBMET, 1992.

MAUÉS, M. M.; COUTURIER, G.. Biologia floral e fenologia de camu-camu (Myrciaria dúbia (H. B. K.) McVaugh, Myrtaceae) no estado do Pará, Brasil. Revista Brasileira de Botânica, São Paulo, v.25, n.4, p.441-448, 2002.

MIRANDA, I. P. A.; RABELO, A.;BUENO, C. R.; BARBOSA, E. M.; RIBEIRO, M. N. S.. Frutos de palmeiras da Amazônia. Manaus: MCT/INPA, 2001.

NASCIMENTO, N. C. C.; MARTORANO, L. G.; BELTRÃO, N. E.; LISBOA, L. S. S.; SODRE, T.; MELO, D.. Panorama espaço temporal de fatores de mudança econômica, social e ambiental na Amazônia: estudo de caso Flona Tapajós. In SEMINÁRIO DE PESQUISAS CIENTÍFICAS DA FLORESTA NACIONAL DO TAPAJÓS, 2. Anais. Tapajós: ICMBio/MMA, 2014.

NÚÑEZ, L. A.. Biología reproductiva y ecologia de la polinización de la palma Milpsos Oenocarpus bataua em los Andes Colombianos. Caldasia, Bogotá, v.30, n.1, p.101-125, 2008. 
NÚÑEZ, L. A.; ISAZA, C.; GALEANO, G.. Ecología de la polinización de três espécies de Oenocarpus (Arecaceae) simpátricas em la Amazonia Colombiana. Revista de Biología Tropical, San José, v.63, n.1, p.35-55, 2015.

OLIVEIRA, M. S. P.; COUTURIER, G.; BESERRA, P.. Biologia da polinização da palmeira tucumã (Astrocaryum vulgare Mart.) em Belém, Pará, Brasil. Acta Botanica Brasilica, Feira de Santana, v.17, n.3, p.343-353, 2003.

PEIXOTO, A. L.; BARBOSA, M. R. V.. Os herbários brasileiros e a flora nacional: desafios para o século 21. 1989.

PINTAUD, J. C.; GALEANO, G.; BALSLEV, H.; BERNAL, R.; BORCHSENIUS, F.; FERREIRA, E.; DE GRANVILLE, J-J.; MEJÍA, K.; MILLÁN, B.; NOBLICK, M. M. R. L.; STAUFFER, F. W.; KAHN, F.. Las palmeiras de América del sur: diversidade, distribucion e história evolutiva. Revista Peruana de Biologia, Lima, v.15, n.1, p.7-29, 2008.

ROSA, L.; CASTELLANI, T. T.; REIS, A.. Biologia reprodutiva de Butia capitata (Martius) Beccari var. odorata (Palmae) na restinga do município de Laguna, SC. Revista Brasileira de Botânica, São Paulo, v.21, n.3, p.281-287, 1998.

RUIZ, R. R.; ALENCAR, J. . Comportamento fenológico da palmeira patauá (Oenocarpus bataua) na reserva florestal Adolpho Ducke, Manaus, Amazonas, Brasil. Acta Amazonica, Manaus, v.34, n.4, p.553-558, 2004.

SILVA, L. S.. A importância do babaçu (Atallea speciosa Mart. ex Spreng.) no processo sucessional em áreas agrícolas no sudeste do estado do Pará. Dissertação (Mestrado em Ciências Florestais) - Universidade Federal Rural da Amazônia, Belém. 2008.

SOUZA FILHO, W. ; MARTORANO, L. G.; BATISTA, V. H. S.; LISBOA, L. S.; MONTEIRO, D. C. A.; MADUREIRA, M. W. S.. Focos de calor no trimestre de menor oferta pluvial como ameaças à perda de biodiversidade na flona tapajós e entorno. In: SIMPÓSIO DE ESTUDOS E PESQUISAS EM CIÊNCIAS AMBIENTAIS NA AMAZÔNIA. Anais. Belém: UEPA, 2012. p.131-131.

SOUZA, H. J. R.; MARTINS-DA-SILVA, R. C. V.; FILER, D. L.; XAVIER JUNIOR, S. R.; FOURO, A. M. M.. Base de dados do herbário IAN da Embrapa Amazônia Oriental. 1 ed. Belém: Embrapa Amazônia Oriental, 2013.

STEEGE, H. T.; PITMAN, N. C. A.; SABATIER, D. Hyperdominance in the Amazonian tree flora. Science, New York, v.342, n.6156, 2013

TALORA, D. C.; MORELLATO, L. P. C.. Fenologia de espécies arbóreas em floresta de planície litorânea do sudeste do Brasil. Revista Brasileira de Botânica, São Paulo, v.23, n.1, p.13-26, 2000

VORMISTO, J.; TUOMISTO, H.; OKSANEN, J.. Palm distribution patterns in Amazonian rainforests: What is the role of topographic variation?. Journal of Vegetation Science, Xalapa, v.15, p.485-494, 2004.

A CBPC - Companhia Brasileira de Produção Científica (CNPJ: 11.221.422/0001-03) detém os direitos materiais desta publicação. Os direitos referem-se à publicação do trabalho em qualquer parte do mundo, incluindo os direitos às renovações, expansões e disseminações da contribuição, bem como outros direitos subsidiários. Todos os trabalhos publicados eletronicamente poderão posteriormente ser publicados em coletâneas impressas sob coordenação da Sustenere Publishing, da Companhia Brasileira de Produção Científica e seus parceiros autorizados. Os (as) autores (as) preservam os direitos autorais, mas não têm permissão para a publicação da contribuição em outro meio, impresso ou digital, em português ou em tradução. 